STUDI

FRANCESI

\section{Studi Francesi}

Rivista quadrimestrale fondata da Franco Simone

190 (LXIV | I) | 2020

Varia - fasc. I - gennaio-aprile 2020

\title{
Une éducatrice des Lumières, Marie Leprince de Beaumont, dir. R. vON KULESSA et C. SETH
}

\section{Elisa Biancardi}

\section{OpenEdition}

\section{Journals}

\section{Edizione digitale}

URL: https://journals.openedition.org/studifrancesi/22681

DOI: 10.4000/studifrancesi.22681

ISSN: 2421-5856

\section{Editore}

Rosenberg \& Sellier

\section{Edizione cartacea}

Data di pubblicazione: 1 avril 2020

Paginazione: 175-176

ISSN: 0039-2944

\section{Notizia bibliografica digitale}

Elisa Biancardi, «Une éducatrice des Lumières, Marie Leprince de Beaumont, dir. R. von KULESSA et C. SETH», Studi Francesi [Online], 190 (LXIV | I) | 2020, online dal 01 mai 2020, consultato il 03 août 2021. URL: http://journals.openedition.org/studifrancesi/22681; DOI: https://doi.org/10.4000/studifrancesi. 22681

Questo documento è stato generato automaticamente il 3 août 2021

\section{(c) (i) () $\Theta$}

Studi Francesi è distribuita con Licenza Creative Commons Attribuzione - Non commerciale - Non opere derivate 4.0 Internazionale. 


\title{
Une éducatrice des Lumières, Marie Leprince de Beaumont, dir. R. VON KULESSA et C. SETH
}

\author{
Elisa Biancardi
}

\section{NOTIZIA}

Une éducatrice des Lumières, Marie Leprince de Beaumont, dir. R. vON KULESSA et C. SETH, Paris, Classiques Garnier, 2018, 283 pp.

1 Nuovo frutto del sodalizio franco-tedesco di R. von Kulessa e C. Seth, Une éducatrice des Lumières si differenzia dalla miscellanea del 2013 (v. "Studi Francesi", 177, 2015, p. 593) per una disamina al contempo più allargata e più approfondita della produzione di Marie Leprince. I saggi di questo volume, suddivisi in tre sezioni, dedicano infatti maggiore spazio ai suoi scritti meno conosciuti e convergono spesso, anche quando prendono le mosse dai suoi magasins più studiati, sulle connessioni fra i principi pedagogico-religiosi dell'educatrice e le istanze filosofico-politiche che pervadono la sua opera. Già il saggio introduttivo di Catriona SETH (Une Idée nouvelle en Europe, pp. 7-15) indica questa direzione, e la sezione centrale «Religion et philosophie», con i suoi sei contributi, si presenta come la più consistente della raccolta. Vari richiami a queste due tematiche arricchiscono comunque anche la prima parte - dal titolo «Une œuvre protéiforme» -, dove Florence BOULERIE (Liberté pour les ladies!, pp. 37-52) e MarieEmmanuelle PLAGNIOL-DIÉVAL (Histoire des passions dans le "Magasin des adolescentes", pp. 19-35) scelgono il medesimo magasin per segnalare rispettivamente la filigrana impegnata che sottende la relazione tra matrimonio e libertà femminile, e la narrazione densa di riferimenti filosofico-religiosi che avvia al buon uso delle passioni. È invece "Le Magasin des pauvres" che solleva gli interrogativi evidenziati da Rotraud VON KULESSA sull'uguaglianza e disuguaglianza sociale nel XVIII secolo (Marie Leprince de Beaumont, "Le Magasin des pauvres" et la démocratisation de l'éducation). Quanto ai romanzi, 
Beatrijs VANACKER (“La Nouvelle Clarice”, pp. 77-90) mostra l'abilità dell'autrice nell'accogliere i gusti letterari del suo tempo per approdare ai fini educativi che la contraddistinguono, mentre Lesley WALKER (In Defence of Fiction, pp. 65-76) individua nelle Lettres de Mme du Montier i segnali di un impegno sociale a largo raggio, fondato su una compresenza di valori religiosi e ideali progressisti.

Come già accennato, questa complementarità tra principi pedagogici, religiosi e filosofico-riformisti trova in seguito specifico risalto nella parte centrale del volume. Ad aprirla è Nicolas BRUCKER che, in Conter la Bible (pp. 93-113), sottolinea la duttilità delle strategie evangelistiche scelte dalla pedagogista per stimolare, grazie alla piacevolezza di fiabe e racconti, un'adesione più spontanea e convinta ai concetti biblici fondamentali. A completarla intervengono poi altri cinque saggi che analizzano la specificità filosofica del cristianesimo illuminato di Marie Leprince: Annette BAUDRON (Les Limites de l'esprit géométrique, pp. 147-160) ritrova una dominante secentesca piuttosto che una reale concezione illuminista nei convincimenti dell'educatrice, mentre l'insistenza di quest'ultima sull'indagine razionale in campo religioso, e il suo recupero in chiave attualizzata del pensiero cartesiano e pascaliano appaiono invece a Jeanne CHIRON («Bien des gens ignorent que le doute méthodique est permis», pp. 115-135) e a Sonia CHERRAD (Marie Leprince de Beaumont, philosophe chrétienne des Lumières, pp. 137-146) altrettanti indicatori della sua modernità di pensiero. Nella stessa direzione vanno anche se in modo più interlocutorio - Ramona HERZ-GAZEAU (La querelle de l'âme des bêtes, pp. 177-193) e Laurence VANOFLEN (Marie Leprince de Beaumont et les Lumières de la raison, pp. 161-176), per le quali l'impronta del Seicento resta visibile, senza però vanificare le corrispondenze tra le opinioni dell'educatrice e quelle dei philosophes.

Infine, la terza parte della miscellanea, dedicata alle «Questions de réception», propone considerazioni su vari aspetti della fortuna letteraria della scrittrice. Dopo il contributo di Béatrice DIDIER su Marmontel e il suo adattamento teatrale de La Belle et la Bête ("Zémire et Azor", pp. 197-203) si passa, più globalmente, ai diversi pareri critici suscitati fra Sette e Ottocento dai tanti successi editoriali di Marie Leprince: Beatriz onANDIA ritraccia le tappe della Fortune littéraire de Marie Leprince de Beaumont en Espagne (pp. 227-242), mentre Alicia C. MONTOYA (Marie Leprince de Beaumont et la littérature médiocre [middlebrow], pp. 205-226) e Nadine BÉRENGUIER (De pédagogue à conteuse. Images de Marie Leprince de Beaumont, pp. 243-265) illustrano i motivi storico-sociali e ideologici che hanno troppo a lungo ostacolato il riconoscimento del ruolo pionieristico e della forte influenza esercitata dalla pedagogista nell'ambito dell'educazione femminile. 